\title{
Extent of Deterioration in Physical Condition during Postoperative Bed Rest and its Reversal by Rehabilitation
}

\author{
E. JOAN BASSEY, P. H. FENTEM
}

British Medical fournal, 1974, 4, 194-196

\section{MEASUREMENT OF PHYSICAL CONDITION}

\section{Summary}

A study has been made of changes in physical condition associated with bed rest and rehabilitation in hospital patients. It was found that after two weeks recumbent bed rest there was a significant decline in physical condition. It was also found that the better the initial physical condition the greater the decline. Rehabilitation was associated with an improvement in physical condition, which seemed to be related to the increased level of daily activity rather than to the absolute levels of physical condition.

\section{Introduction}

Physical condition, assessed in terms of the cardiorespiratory response to exercise, is known to deteriorate during recumbent bedrest (Saltin, et al., 1968). It may be possible to limit the extent of this deterioration in hospital patients by early mobilization after surgery or an acute illness, but such a regimen is not always feasible. Alvik (1966) proposed instead the use of training programmes before elective surgery. Adolfsson (1969) tested this proposal in 63 women with a six-week training programme before an elective cholecystectomy. Though their work capacity improved as a result of training, 10 days after operation it was not significantly different from that of patients who had not undertaken preoperation training.

We report here a comparison of preoperative and postoperative observations made on a group of patients who were recumbent in bed for two weeks. The aim was to determine whether good physical condition at the time of admission to hospital influenced favourably the degree of deterioration due to bed rest. The study was also concerned with the extent of the improvement which had occurred at the end of the first two weeks' active rehabilitation and the extent to which the improvement matched the earlier deterioration.

\section{Methods}

Nine men, aged 20 to 47 years (mean 33 years), were admitted to an orthopaedic hospital for the removal of a cartilage from one knee. They had all had troublesome knees for more than two months. These patients were chosen for study since they would be required to remain in bed after operation for two weeks but the operative procedure itself would not be expected to interfere with cardiovascular or respiratory function. None of the patients had signs or symptoms of cardiorespiratory disease and their resting E.C.G. was normal. The patients gave their informed consent.

\footnotetext{
Department of Physiology, Medical School, University of Nottingham, Nottingham NG7 2RD

E. JOAN BASSEY, B.SC., Research Assistant

P. H. FENTEM, M.SC., M.B., Reader in Physiology
}

One measure of physical condition is obtained by relating the magnitude of a physical task, as determined by the oxygen uptake required to complete the task, to the cardiovascular response (Cotes, 1971). The response may be conveniently estimated by measuring the heart rate. Physical condition is then expressed as the heart rate at a standard oxygen uptake.

Each subject performed exercise tests on a modified bicycle ergometer. Since the subject had one damaged knee he pedalled the bicycle with his sound leg only. The damaged leg rested on a stool. A counterweight $(3.2 \mathrm{~kg})$ was fixed to the unused pedal in order to facilitate a smooth pedalling action. The exercise test consisted of working at three submaximal rates (nominally 25,50, and 75 watts) for a time sufficient for the heart rate to reach a steady value (3-5 $\mathrm{min}$ ). Subjects rested for five minutes between the second and third load. Heart rate, arterial blood pressure, oxygen uptake, and carbon dioxide output were measured during the last minute at each work load (Bassey et al., 1973).

Preliminary studies had established that there is a linear relation between heart rate and oxygen uptake during pedalling with one leg (Bassey and Goldsmith, 1974) as there is pedalling with two legs (Astrand, 1956). It was therefore possible to obtain the required measurement of heart rate at a standard oxygen uptake by using the three recorded points to obtain a regression line and then interpolating. This was done for each subject at each test (fig. 1). A standard value of $1.21 . / \mathrm{min}$ for oxygen uptake was chosen because this allowed interpolation rather than extrapolation in all but one case. Comparisons were made using Student's $t$ test for paired means.

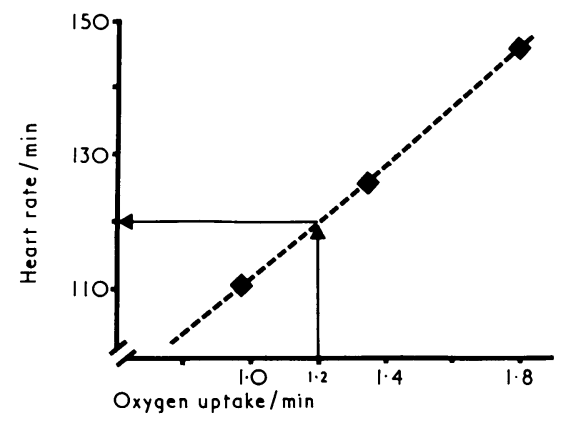

FIG. 1-Procedure for standardization of results. Regression line was drawn for results of one test. Heart rate was related to oxygen consumption at three different work loads.

\section{EXPERIMENTAL DESIGN}

Subjects performed exercise tests on at least two occasions before operation and the results from the second test were used as the preoperative baseline. Postoperative tests were performed at two weeks when the subjects were first allowed out of bed and with seven out of the nine patients again at four weeks, after two weeks ambulation and physiotherapy.

\section{REHABILITATION PROGRAMME}

During the two weeks spent in bed after the operation the patients received instructions to perform static contractions of 
the quadriceps of the operated leg hourly during the day. In addition, physiotherapists conducted a brief ward class of chest and upper limb exercises when possible.

After bed rest the rehabilitation programme included graduated exercise in the gymnasium and pool. The programme was designed so that all patients would be able to meet the full physical demands of their job on discharge.

\section{Results}

Effects of Bed Rest.-Using the standardization procedure described above the mean value for the heart rate $( \pm 1$ S.E.) during the exercise test before operation, at an oxygen uptake of $1.21 . / \mathrm{min}$, was $119 \pm 6.2$ beats $/ \mathrm{min}$. Two weeks after operation the corresponding value was $127 \pm 4.0$ beats $/ \mathrm{min}$. This indicated that the physical condition of the patients, in this respect at least, had deteriorated, and the change was significant $(P<0.05)$.

When the individual changes in physical condition expressed in terms of heart rate were related to the initial values (fig. 2) it seemed that those with the best physical condition deteriorated most.

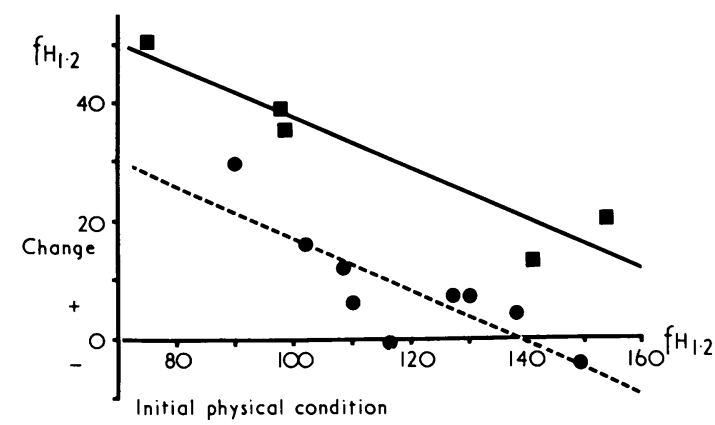

FIG. 2-Relation between initial physical condition expressed as standardized heart rate $\left(\mathrm{fH}_{1 \cdot 2}\right)$ and the change in physical condition $\left(\mathrm{fH}_{1.2}\right)$ experienced by nine patients after two veeks bed rest (present study, $O$ ), and by five subjects after 20 days bed rest (Saltin et al. (1968) $)$ ).

Effects of Rehabilitation.-Seven of the patients were studied again after the first two weeks' rehabilitation (four weeks after operation). Two patients had such light occupations that they were allowed to leave hospital after less than two weeks' rehabilitation. The mean value for the heart rate during the exercise test after this period of rehabilitation was $120 \pm 4.64$ beats $/ \mathrm{min}$ at an oxygen uptake of $1.21 . / \mathrm{min}$, and the preoperative value for the same seven patients was almost identical, being $120 \pm 7 \cdot 52$ beats $/ \mathrm{min}$. The individual differences between the initial physical condition and the condition after rehabilitation are presented in fig. 3, Those in the best initial physical condition failed to return to it and those in poor initial condition were improved beyond their initial state.

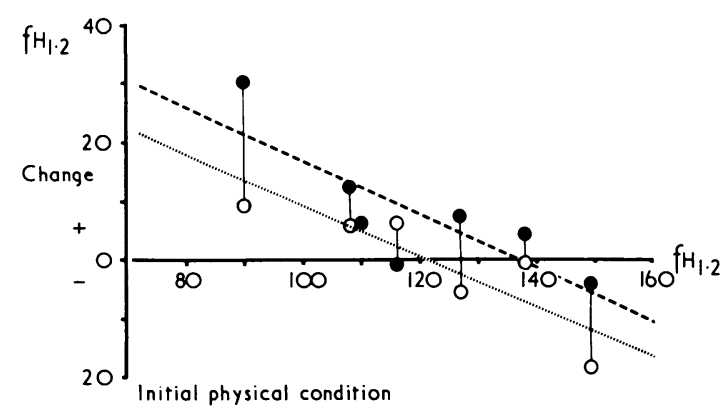

FIG. 3-Improvement with rehabilitation expressed as standardized heart rate $\left(\mathrm{fH}_{1 \cdot 2}\right)$ = After two week's bed rest. $\mathbf{O}=$ After two weeks' rehabilitation. Single point refers to one subject who showed no change.
Analysis of Data Presented by Saltin et al. (1968).- Saltin et al. (1968) made a study of five young men who voluntarily spent three weeks recumbent in bed. They included both athletic and sedentary subjects. The results of their study were presented in detail and could be analysed in the same way as the data in the present study-that is, changes in physical condition with bed rest and rehabilitation could be expressed as heart rate at an oxygen uptake of $1.21 . / \mathrm{min}$. It was found that the mean value for heart rate before bed rest was $113 \pm 6.6$ beats $/ \mathrm{min}$, after bed rest it rose to $145 \pm 3.9$ beats $/ \mathrm{min}$, and after rehabilitation dropped back to $106 \pm 3.3$ beats $/ \mathrm{min}$. The results were found to be similar to those in our study both in the relation between initial physical condition and the deterioration due to bed rest and in the relation between initial condition and the improvement due to rehabilitation (fig. 4). The only difference was that both deterioration and improvement were greater in the study of Saltin et al.

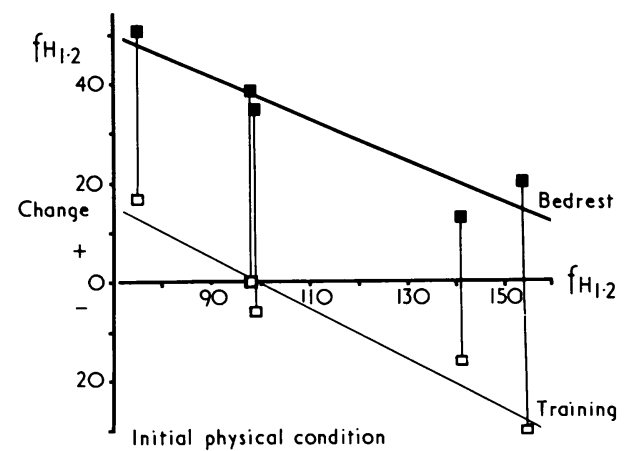

FIG. 4-Improvement with rehabilitation (Saltin et al., 1968) expressed as standardized heart rate $\left(\mathrm{fH}_{1 \cdot 2}\right)$. $\square=$ After two weeks' bed rest. $\square=$ After two weeks' rehabilitation.

\section{Discussion}

Effects of Bed Rest.-The finding that two weeks' postoperative bed rest caused a deterioration in the physical condition of this group of hospital patients is in agreement with other reports of the effect of bed rest on healthy volunteers (Taylor et al., 1949; Saltin et al., 1968). The deterioration, however, ranged from $0 \%$ to $33 \%$. An explanation for this variation was sought in the initial physical condition, which was also found to range widely (90-154 beats/min in standardized heart rate). It was found that the subjects who were in the best physical condition before operation (with low standardized heart rates) deteriorated the most and those who were in poor physical condition (with high standardized heart rates) deteriorated least (see fig. 2). In the study reported by Saltin et al. (1968) the subjects also deteriorated by a variable amount, $9 \%$ to $68 \%$. As in the present study those who were in the best condition before bed rest deteriorated the most and those who were in the poorest condition before bed rest deteriorated the least. The major difference between their results and those of the present study was that Saltin's subjects deteriorated to a greater extent. The rise in standardized heart rate was about 20 beats/min greater. The difference may be explained by two contributory factors. Saltin's subjects were in bed for nearly a week longer and our patients were expected to do exercises in bed. Miller et al. (1965) found a progressive deterioration with bed rest over a few weeks, but the evidence for the protective effects of exercise in bed is conflicting (Miller et al., 1965; Rodahl et al., 1967).

Effects of Rehabilitation.-The hospital rehabilitation programme was directed mainly at improving the function of the operated knee, but it did produce in two weeks a significant improvement in the general physical condition of the group. The improvement was small ( 7 beats $/ \mathrm{min}$ in standardized heart rate) and seemed to be related to the increase in 
activity levels which was common to all the subjects rather than to the absolute levels of physical condition. Those who had been in the best condition before operation were not fully restored by two weeks rehabilitation, and those who had been in poor condition before operation improved over and above their initial condition. The results of Saltin et al. (1968) were similar except that the improvement due to rehabilitation was very much greater (a decrease of about 40 beats $/ \mathrm{min}$ in standardized heart rate) owing to the severity and length of the programme (eight weeks strenuous interval training at near maximum work rates). As in the present study the improvement seemed to be related to the degree of change in activity levels and not to the absolute levels of physical condition.

Conclusion.-In principle, prophylactic training for elective surgery is attractive. Any measure which may reduce the impact of surgery and accelerate recovery is of importance. This study suggests that good physical condition at the time of hospital admission does not prevent deterioration in physical condition during bed rest or influence the benefits to be derived from rehabilitation. These conclusions apply to only one aspect of cardiospiratory function.
This investigation formed part of a project supported by a grant from the Nuffield Foundation. We thank the staff of Harlow Wood Orthopaedic Hospital, near Mansfield, for their encouragement, the provision of facilities, and their co-operation. We are particularly grateful to Mr. N. J. Barton, Mr. J. P. Campbell, Mr. J. S. Hopkins, Mr. J. P. Jackson, Dr. K. Lloyd-Jones, and Mr. W. Waugh for permitting us to study patients admitted under their care.

\section{References}

Adolfsson, G. (1969). Scandinavian fournal of Rehabilitation Medicine $1,14$.

Alvik, I. (1966). In Physical Activity in Health and Disease, ed. K. Evang and $\mathrm{K}$. Lange Anderson. Baltimore, Williams and $W$ ilkins.

Astrand, P. O. (1956). Physiological Reviews, 36, 307.

Bassey, E. J., et al. (1973). Cardiovascular Research, 7, 588.

Bassey, E. Joan and Goldsmith, R. (1974). Scandinavian fournal of Rehabilitation Medicine. In press.

Cotes, J. E. (1971). Scandinavian fournal of Respiratory Diseases, Suppl. No.

M7, p. 123. 36, 1077 .

Rodahl, K., et al. (1967). In Nutrition and Physical Activity, ed. G. Blix, p. 107. Stockholm, Almqvist and Wiksell.

Saltin, B., et al. (1968). Circulation, 38, Suppl. No. 7, p. 1.
Taylor, H. L., et al. (1949). Fournal of Applied Physiology, 2, 233.

\section{Simple Analgesics for Arthritis}

\section{E. C. HUSKISSON}

\author{
British Medical fournal, 1974, 4, 196-200
}

\section{Summary}

A series of experiments has been carried out with single doses of simple analgesics in patients with rheumatoid arthritis using a consistent polyad design. This method proved to be both valid and useful. Pain relief scores were a better measure of the effectiveness of analgesics than preference.

Aspirin, Codis, and Distalgesic were the most effective analgesics tested, with paracetamol, pentazocine, and Ciba 44,328 intermediate between these agents and placebo. Placebo given after an active analgesic was more effective than when given before; this phenomenon was not abolished by telling the patients that apparently identical tablets were, in fact, different or by making them different in colour. The effectiveness of soluble placebo depended on its colour, red being the most effective.

\section{Introduction}

It is conventional to supplement regular anti-inflammatory drug therapy for rheumatoid arthritis with single doses of simple analgesics, the patient being instructed to take some tablets when pain is uncontrolled. If analgesics are not provided many patients will obtain them without prescription. In a previous study (Huskisson and Hart, 1972 a) patients with rheumatoid arthritis were found to take an average of 9.2 tablets daily, of which 4.2 were simple analgesics taken "on demand"; the number of tablets taken was related to the patient's pain threshold as well as to the severity of the disease.

St. Bartholomew's Hospital, London. EC1A 7BE

E. C. HUSKISSON, M.D., M.R.C.P., Senior Lecturer in Rheumatology
The object of this study was to find a suitable experimental design for testing simple analgesics in patients with arthritis and to use this design to test some of the available drugs. Some conditions were imposed on the experiment in advance. Firstly, since there are a large number of analgesics from which to choose the method had to be capable of testing large numbers of compounds. Secondly, since simple analgesics are given in single doses for uncontrolled pain they had to be tested in this way. Thirdly, the design had not to require an impossibly large sample size, and it was anticipated that about 24 patients would be readily available for such an experiment. This combined with the need to test large numbers of compounds made a cross-over design essential. Fourthly, the method had to be directed towards the measurements of effectiveness in terms of pain relief; toxicity could be studied in separate, long-term experiments designed for the purpose which would give the opportunity for the demonstration of other important phenomena such as interactions with regular treatment.

Three experiments are reported here, the first comparing analgesic tablets, the second soluble analgesics in different colours, and the third a new analgesic with a standard and placebo. The trials were designed to take advantage of the consistent polyad method described by Kendall (1963) and used previously (Huskisson and Hart, 1972 b) in a trial of single doses of anti-inflammatory drugs. This method is ideal for multiple comparisons because every possible pair of treatments is directly compared and the variability between first and last is thereby minimized.

\section{Methods}

Thirty patients were admitted to the first trial, 24 to the second, and 24 to the third. All had definite or classical rheumatoid anthritis (A.R.A. criteria; Ropes et al., 1959), with pain of sufficient severity to require "on-demand" analgesics at least once a day. 